\title{
Knowledge of diabetes and hypertension among members of teaching staff of higher learning institutions in Dar es Salaam, Tanzania
}

\author{
FAIDA E. MBUYA ${ }^{1 *}$, FRANCIS FREDRICK ${ }^{2}$ and BEATUS KUNDI ${ }^{3}$ \\ ${ }^{1}$ Management and Development for Health, P.O. Box 79810, Dar es Salaam, Tanzania \\ ${ }^{2}$ Department of Paediatrics and Child Health, School of Medicine, Muhimbili University of Health, Dar es \\ Salaam, Tanzania \\ ${ }^{3}$ College of Engineering and Technology, University of Dar es Salaam, Tanzania
}

\begin{abstract}
Diabetes and hypertension are among the most common non-communicable diseases (NCD) that contribute to a large number of adult morbidity and mortality. The objective of this study was to determine knowledge of diabetes and hypertension and the associated risk factors among members of teaching staff of Higher Learning Institutions in Dar es Salaam, Tanzania. A cross sectional community based study was conducted in 10 higher learning institutions including universities. A structured pretested questionnaire was utilized. A total of 139 teaching members of staff from higher learning institutions participated in the study. The majority $(74.8 \% ; n=104)$ of the participants were males. Mean age of the participants was $40.7 \pm$ 12.6. Over half $(56.8 \% ; 79 / 139)$ of the respondents correctly identified failure of body to use insulin as one of the causes of diabetes. Of the respondents, $43.2 \%$ (60/139) were able to identified heredity as cause of hypertension. Increasing age was correctly identified as one of risk factors for diabetes by $38.1 \%$ (53/139) and for hypertension by $36.7 \%$ (51/139) respondents. In conclusion, the majority of teaching staff in the higher learning Institutions in Dar es Salaam were aware of the diabetes and hypertension. However the knowledge of the causes, signs and symptoms, risk factors and complications was not as high as expected. It is important that this group of professionals is appropriately informed as regards to diabetes, hypertension and other non-communicable diseases as they may serve as key advocacy group to the community and policy makers in Tanzania.
\end{abstract}

Keywords: diabetes mellitus, hypertension, knowledge, academic staff, Tanzania

\section{Introduction}

Non-communicable diseases (NCD) are on the rise globally especially in the low and middle income countries where initially it was assumed the burden of these diseases was uncommon (WHO, 2006). Among the most common types of NCD are the diabetes and hypertension. In a number of African countries these chronic diseases contribute to a larger number of adult medical admissions and deaths compared to infectious diseases like HIV/AIDS or tuberculosis (Aikins et al., 2010). Though communicable diseases remain the major cause of morbidity and mortality in Tanzania, the contribution of NCD on burden of diseases is considerably high. Between 18 and $24 \%$ of deaths in Tanzania are reported to be due to NCD and injuries (AMMP, 1997). In Tanzania, the major non-communicable diseases contributing most to overall mortality and morbidity include cardiovascular diseases, cancer, central nervous system diseases, diabetes and chronic respiratory disease (AMMP, 1997; WHO, 2012; Mfinanga et al., 2012; Mayige et al., 2012).

Both hypertension and diabetes mellitus are prevalent in Tanzania (Mfinanga et al., 2012; Mayige et al., 2012). Manumbu (2011) reported a prevalence of hypertension (systolic $\geq 140$ or diastolic $\mathbf{2 0 0}$ ) of $44.4 \%$ for males and of $44.8 \%$ for females. Other previous studies have reported hypertension prevalence of 28.6-31.5\% among women and 27.1\% to 32.2\% among men (Edwards et al., 2000; Bovet et al., 2002). A recent study in in Tanzania has reported a diabetis mellitus prevalnce of 9.1\% (WHO, 2012). The prevalence of diabetes is higher among urban than among rural communities (Ramaiya et al., 1991; Aspray et al., 2000). The increasing trend in NCD is likely

* Correspondence: Faida Emil; Email: mkafaida@gmail.com 
to influence an increase in workload for healthcare workers who need to be prepared in managing such diseases (Kwesigabo et al., 2012).

The success of any disease control programme depends on community knowledge and practices as regards to risk factors, treatment and prevention. It is envisaged that high knowledge and awareness of these conditions will prompt people to seek health care timely and reduce possibilities of developing complications. Several studies have documented that lack of community awareness on communicable diseases could contribute to the spread of the diseases, hinder control strategies and increase risk of exposure to the diseases (Mboera et al., 2009; Imbahale et al., 2010). There is scarcity of studies on knowledge of diabetes and other noncommunicable diseases in developing countries, and the few available reports are hospital based focusing on awareness of diseases among patients (Mohan et al. 2005). Although a number of non-communicable disease are currently been managed through medical interventions, there is need for appropriate knowledge of a disease should be promoted. Various studies conducted in many parts of the world showed that there is lack of awareness and knowledge of various risk factors associated with diabetes among people (Murugesan et al., 2007; Al Shafaee et al., 2008). In Tanzania, the low knowledge of diabetes mellitus in the general population has been to the late diagnosis and management of diabetic patients (Nguma, 2010). This objective of this study was to evaluate the knowledge of diabetes mellitus and hypertension among staff members of higher learning institutions in Dar es Salaam, Tanzania.

\section{Materials and Methods}

\section{Design data collection}

This was a community based descriptive cross-sectional study that was conducted between November 2011 and March 2012. Ten higher learning institutions namely Universities of Dar es Salaam (UDSM), Ardhi University (ARU), College of Business Education (CBE), Institute of Finance Management (IFM), Institute of Social Work, Mzumbe University, Open University of Tanzania, School of Journalism and Mass Communication (SJMC), Tanzania Institute of Accounts (TIA) and Dar es Salaam University College of Education (DUCE) were involved in this study. All teaching faculties were eligible for this study. Sample size for this study was determined by a formula described by Kish (1965) giving a minimum sample size of 118. A total of 155 questionnaires were distributed using convenient sampling.

Structured pre-tested self-administered questionnaire was utilized to collect information for this study. Questionnaire was divided into four parts; the first part was about the demographic information of the participant, the second part was on general health, the third part was about knowledge of diabetes and hypertension and the fourth was on the source of information regarding diabetes and hypertension.

\section{Data analysis}

Filled questionnaires were coded before entering into the computer, data cleaning and analysis were performed using Statistical Package for Social Sciences (SPSS) version 18 and frequency distribution tables were used to summarize the data. A total of 142 filled questionnaires were gathered giving response rate of 91.6\%; however 3 were inappropriately filled and were excluded from analysis.

\section{Ethical considerations}

Ethical clearance was approved by the Department of Research of the University of Dar es Salaam and permission to conduct this study was sought from each institution. Written informed consent was sought from each participant prior to recruitment.

\section{Results}




\section{Demographic characteristic of participants}

A total of 139 teaching members of staff from higher learning institutions in Dar es Salaam participated in the study. Majority $(74.8 \% ; \mathrm{n}=104)$ of the participants were males. Mean age of the participants was $40.7 \pm 12.6$. The age group $25-34$ years constituted the majority of the respondents. Most $(55.4 \% ; n=77)$ of the study participants were assistant lecturers. Thirteen (9.4\%) and $19(13.7 \%)$ of the participants reported to suffer from diabetes and hypertension, respectively (Table 1 ).

Table 1:- Demographic characteristic of participants

\begin{tabular}{lll}
\hline Variable & Response & Frequency (\%) \\
\hline Age group (years) & $<25$ & $2(1.4 \%)$ \\
& $25-34$ & $49(35.3 \%)$ \\
& $35-44$ & $44(31.7 \%)$ \\
& $45-54$ & $29(20.9 \%)$ \\
Sex & $55-64$ & $14(10.1 \%)$ \\
Teaching position & $>64$ & $1(0.7 \%)$ \\
& Female & $35(25.2)$ \\
& Male & $104(74.8)$ \\
& Tutorial assistant & $25(18)$ \\
& Assistant lecturer & $77(55.4)$ \\
& Lecturer & $20(14.4)$ \\
& Senior lecturer & $15(10.8)$ \\
\hline
\end{tabular}

Knowledge of causes, signs and symptoms, risk factors and complication of diabetes mellitus

Seventy nine (56.8\%) participants correctly identified failure of body to use insulin as one of the causes of diabetes mellitus whereas 22 (15.8\%) identified certain drugs as causes of diabetes mellitus. The signs and symptoms of diabetes were correctly identified by a number of participants with exception of symptom of excessive hunger $27(19.4 \%)$. Of all participants $65.5 \%$ (91/139) agreed that both diabetes and hypertension can be prevented. On the risk factors for diabetes, only 38.1\% (53/139) of participants correctly identified increasing age as one of the risks. Regarding complications, $37.4 \%$ and $41 \%$ of participants correctly identified hypertension and heart failure respectively as complication of diabetes.

Table 2: Knowledge of causes, signs and symptoms, risk factors and complication of diabetes mellitus

\begin{tabular}{llll}
\hline Variable & Response & $\begin{array}{l}\text { Correct response } \\
\text { No (\%) }\end{array}$ & $\begin{array}{l}\text { Incorrect response } \\
\text { No (\%) }\end{array}$ \\
\hline Causes & Lack of insulin & $70(50.4 \%)$ & $69(49.6 \%)$ \\
& Failure of body to use insulin & $79(56.8 \%)$ & $60(43.2 \%)$ \\
Signs and symptoms & Certain drugs & $22(15.8 \%)$ & $117(84.2 \%$ \\
& Frequent urination & $119(85.6 \%)$ & $20(14.4 \%)$ \\
& Excessive thirst & $74(53.2 \%)$ & $65(46.8 \%)$ \\
Excessive hunger & $27(19.4)$ & $112(80.6 \%)$ \\
Risk factors & Weight loss & $71(51.1 \%)$ & $68(48.9 \%)$ \\
& Decrease sexual abilities & $72(51.8 \%)$ & $67(48.2 \%)$ \\
& Decreased physical activity & $92(66.2 \%)$ & $47(33.8 \%)$ \\
& Obesity & $87(62.6 \%)$ & $52(37.4 \%)$ \\
& Family history of diabetes & $76(54.7 \%)$ & $63(45.3 \%)$
\end{tabular}




\begin{tabular}{llll} 
& Increasing age (elderly) & $53(38.1 \%)$ & $86(61.9 \%)$ \\
Complications & Loss of vision & $91(65.5 \%)$ & $48(34.5 \%)$ \\
& Kidney failure & $82(59 \%)$ & $57(41 \%)$ \\
& Heart failure and stroke & $57(41 \%)$ & $82(59 \%)$ \\
& Delayed wound healing & $105(75.5 \%)$ & $34(24.5 \%)$ \\
& Hypertension & $52(37.4 \%)$ & $87(62.6 \%)$ \\
\hline
\end{tabular}

Knowledge of causes, signs and symptoms, risk factors and complication of hypertension Hereditary was correctly recognized by $43.2 \%$ of participants as the cause of hypertension and certain drugs by only $17.3 \%$. The symptom of hypertension of headache was correctly identified by $68.3 \%$ of participants. On the risk factors for hypertension few participants correctly identified elderly age (36.4\%) and family history of hypertension (41.7\%) as among the factors that increase risk of getting hypertension. Among the participants, $69.8 \%$ did not identify kidney failure to be one of the complications of hypertension.

Table 3: Knowledge of causes, signs and symptoms, risk factors and complications of hypertension

\begin{tabular}{llll}
\hline Variable & Response & $\begin{array}{l}\text { Correct response } \\
\text { No }(\%)\end{array}$ & $\begin{array}{l}\text { Incorrect response } \\
\text { No (\%) }\end{array}$ \\
\hline Causes & Stress & $102(73.4 \%)$ & $37(26.6 \%)$ \\
& Hereditary & $60(43.2 \%)$ & $79(56.8 \%)$ \\
Signs and symptoms & $24(17.3 \%)$ & $115(82.7 \%$ \\
& Certain drugs & $95(68.3 \%)$ & $44(31.7 \%)$ \\
& Headache & $35(25.2 \%)$ & $104(74.8 \%)$ \\
& Confusion & $65(46.8 \%)$ & $74(53.2 \%)$ \\
Risk factors & Drowsiness & $54(38.8 \%)$ & $85(61.2 \%)$ \\
& Vision impairment & $76(54.7 \%)$ & $63(45.3 \%)$ \\
& Alcoholism & $53(38.1 \%)$ & $86(61.9 \%)$ \\
& Smoking & $70(50.4 \%)$ & $69(49.6)$ \\
High salt diet & $51(36.7 \%)$ & $88(63.3 \%)$ \\
Increasing age & $84(60.4 \%)$ & $55(39.6 \%)$ \\
& Obesity & $58(41.7 \%)$ & $81(58.3$ \\
& Family history & of & $97(69.8 \%)$ \\
& hypertension & $42(30.2 \%)$ & $48(34.5 \%)$ \\
& Kidney failure & $91(65.5 \%)$ & $40(28.8 \%)$ \\
\hline
\end{tabular}

\section{Sources of Information regarding diabetes and hypertension}

The major source of information for diabetes and hypertension was internet and media ( $84 \%$ and $73.4 \%$ respectively) whereas the least reported source of information was family member $(48.2 \%)$ (Figure 1). Encompass 


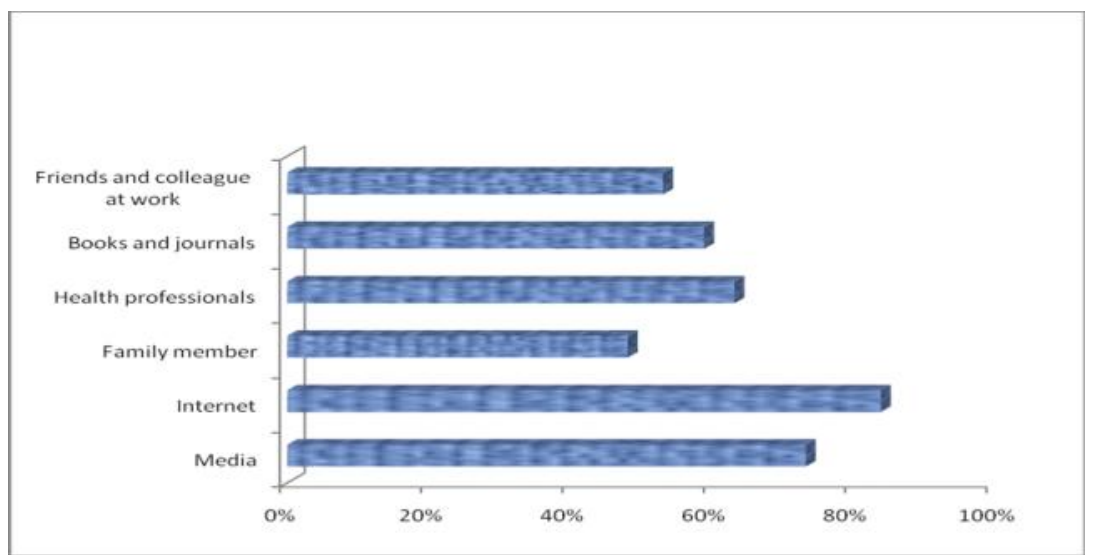

Figure 1: Source of information regarding diabetes and hypertension Discussion

The study examined knowledge of diabetes and hypertension among the highly educated population sample. Findings from the study revealed that majority of the participants had knowledge of two or more factors related to cause, signs and symptoms, risks or complication of the diseases. Majority of the respondents (65.5\%) correctly recognized that diabetes and hypertension are preventable conditions. In a similar study in India, only $42.6 \%$ of the educated and professional respondents recognized that diabetes could be prevented (Mohan et al., 2005). About three quarters of university students in United Arab Emirates reported to be aware that diabetes could be prevented (Khan et al., 2012). In a study in Oman, a higher level of education, a higher household income, and the presence of a family history of diabetes were found to be positively associated with more knowledge (Al Shafee et al., 2008). Finding from our study and other reports shed lights on the importance of education in fostering life style changes to prevent these conditions.

Concerning causes of diabetes some respondents correctly linked aetiology of diabetes to lack of insulin and failure of body to use insulin. The respondents had a fair knowledge of signs and symptoms of diabetes. However, excessive hunger as a symptom of diabetes was correctly identified by only about one-fifth of the respondents. This was in contrast to findings of a study in Saudi Arabia (Mohieldein et al., 2012) where about one-third of the respondents were aware of symptoms of diabetes mellitus. Adequate knowledge of symptoms is an important attribute for early diagnosis and timely diabetes management to prevent complications. The proportion of participants who correctly reported on hereditary as the cause of hypertension was lower than half. Similar findings were reported by Abdulahi et al. (2011) among the staff of the University of Ibadan in Nigeria whereby it was observed that only a few respondents could link heredity to hypertension. In another study among non-academic staff elsewhere in Nigeria, Adika et al. (2011) reported over half the respondents to have correctly reported the link between hypertension and heredity. On the other hand, findings of this study slightly over half of the respondents could not link positive family history of hypertension and acquiring of hypertension. Similar findings have been reported elsewhere in Tanzania (Mlunde, 2007) and Nigeria (Abdullahi \& Amzati, 2011). Failure to recognize the risk factors diminishes the ability to prevent oneself from the disease.

The study revealed that majority of respondents had correct knowledge of heart failure and stroke and loss of vision as complications of hypertension but less than one-third recognized kidney failure as one of complications. On the other hand knowledge of complications of diabetes was low particularly with respect to heart failure, stroke and hypertension which were correctly identified by less than half of the participants. Poor knowledge regarding the complications of diabetes has also been reported among diabetic patients in India, more so among women (Gulabani et al., 2008). 
Internet and media were the two major sources of information reported by participants; other sources included books, journals, friends and health care providers. These findings differs with those reported by studies conducted among non-academic participants who reported the major sources to be friends, family, and media (Mohieldein et al., 2011; Oladapo et al., 2013). This difference could be accounted for by the difference in the study population in which case participants in our study were teaching staff at higher learning institutions who uses internet frequently. The reported sources of information could be effectively utilized to pass health education messages to the population and improve awareness of the community on these two conditions. In this study, healthcare providers were also identified as an important source of health education, more than what was reported from a study in Singapore (Wee et al., 2013).

It is evident from findings in this study that majority of teaching staff in the higher learning Institutions in Dar es Salaam were aware of the diabetes and hypertension. However the knowledge of the causes, signs and symptoms, risk factors and complications was not as high as expected considering the respondents were among the highly educated and professional population. It is important that this group of professionals is appropriately informed as regards to diabetes, hypertension and other non-communicable diseases as they may serve as key advocacy group to the community and policy makers in Tanzania.

\section{Acknowledgments}

This work was made possible because of the contributions and support of several people and institutions, our sincere thanks go to everyone particularly the Principals and administration of all the ten higher learning institutions and all the teaching members of staff who keenly participated in this study.

\section{Conflict of interest}

The authors have no conflict of interest in connection with this article.

\section{References}

Abdullahi, A.A. \& Amzat, J. (2011) Knowledge of hypertension among the staff of University of Ibadan, Nigeria. Journal of Public Health and Epidemiology 3, 204-209.

Adika, V.O., Joffa, P.P.K. \& Apiyanteide, F.A. (2011) Hypertension knowledge among nonacademic employees of Niger Delta University, Bayelsa State, Nigeria. International Journal of Tropical Medicine 6, 113-120.

Aikins, A.G., Boynton, P. \& Atanga, L.L. (2010) Developing effective chronic disease intervention in Africa: Insights from Ghana and Cameroon. Globalization and Health 6:6

Al Shafaee, M.A., AL-Shukaili, S., A Rizvi, S.G., Al Farsi, Y., Khan, M.A., Ganguly, S.S., Afifi, M. \& Al

Adawi, S. (2008) Knowledge and perceptions of diabetes in a semi-urban Omani population. BMC Public Health 8, 249.

Gulabani, M., John, M. \& Isaac, R. (2008) Knowledge of diabetes, its treatment and complications amongst diabetic patients in a tertiary care hospital. Indian Journal of Community Medicine 33, 204-206.

Imbahale, S.S., Fillinger, U., Githeko, A., Mukabana, W.R., Takken, W. (2010) An exploratory survey of malaria prevalence and people's knowledge, attitudes and practices of mosquito larval source management for malaria control in western Kenya. Acta Tropica 115, 248-256. 
Khan, N., Gomath, K.G., Shehnaz, S.I. \& Muttappallymya, J. (2012) Diabetes mellitus -related knowledge among university students in Amjan, United Arab Emirates. Sultan Qaboos University Medical Journal 12, 306-314.

Kish, L. (1965) Survey Sampling. New York: John Wiley and Sons, Inc.

Kwesigabo, G., Mwangu, M.A., Kakoko, D.C., Killewo, J. (2012) Health challenges in Tanzania: Context for educating health professionals. Journal of Public Health Policy 33, S23-S34

Maina, W.K., Ndegwa, Z.M, Njenga, E.W. \& Muchemi, E.W. (2011) Knowledge, attitude, and practices related to diabetes among community members in four provinces in Kenya: a cross-sectional study. African Journal of Diabetes Medicine 19, 15-18.

Mayige, M., Kagaruki, G., Ramaiya, K., Swai, A. (2011) Non-communicable diseases in Tanzania: a call for urgent action. Tanzania Journal of Health Research 13(5). http://dx.doi.org/10.4314/thrb.v13i5.7

Mboera, L.E.G., Shayo, E.H., Senkoro, K.P., Rumisha, S.F., Mlozi, M.R.S., Mayala, B.K (2010) Knowledge, perceptions and practices of farming communities on linkages between malaria and agriculture in Mvomero District, Tanzania. Acta Tropica 113, 139-144.

Mfinanga, S.G.M., Ezekiel, L., Sokoine, K., Ngadaya, E., Mghamba, J., Ramaiya, K. (2011) Public health concern along side with global initiative on the priority action for "silent uprising epidemic" on Non-Communicable Diseases in Tanzania. Tanzania Journal of Health Research 13 (5), http://dx.doi.org/10.4314/thrb.v13i5.6

Mlunde, L. (2007) Knowledge, attitude and practices towards risk factors for hypertension in Kindondoni Municipality, Dar es Salaam. Dar es Salaam Medical Student Journal 14, 59-62

Mohan, D., Raj, D., Shanthirani, C.S., Datta, M., Unwin, N.C., Kapur, A. \& Mohan, V. (2005). Awareness and Knowledge of Diabetes in Chennai-The Chennai Urban Rural Epidemiology Study [CURE-9]. IAPI 53, 283-287.

Mohieldein, A.H., Alzohairy, M.A. \& Hasan, M. (2011) Awareness of diabetes mellitus among Saudi non-diabetic population in Al-Qassim region, Saudi Arabia. Journal of Diabetes and Endocrinology 2, 14-19.

Nguma, L.K. (2010) Health Seeking and Health related behavior for type 2 diabetes mellitus among adults in an urban community in Tanzania. PhD Thesis, University of Otago, New Zealand.

Oladapo, O.O., Salako, L., Sadiq, L., Soyinka, K. \& Falase, A.O. (2013) Knowledge of hypertension and other risk factors for heart disease among Yoruba rural southwestern Nigerian population. British Journal of Medicine \& Medical Research 3, 993-1003.

Wee, H.L., Ho, H.K. \& Li, S.C. (2002) Public awareness of diabetes mellitus in Singapore. Singapore Medical Journal 43, 128-134.

WHO (2006) An Estimation of the Economic Impact of Chronic Non-Communicable Diseases In Selected Countries. World Health Organization, Geneva. 